\title{
DESIGN HOSPITALAR: \\ Uma proposta de metodologia para o desenvolvimento de um carrinho de leitura, com foco no ergodesign e na ludicidade
}

Sandro Alisson Neris dos Santos

Juliana Donato de Almeida Cantalice

Resumo: O processo de internação em uma unidade hospitalar pode comprometer o paciente no que compete as suas dimensões, físicas, sociais e culturais, assim, o presente trabalho vendo a atuação do designer no âmbito hospitalar, apresenta um estudo realizado com o grupo Sorriso de Plantão, de Maceió - AL, com a proposta do desenvolvimento de um produto que possa através da atividade lúdica, auxiliar o tratamento dos pacientes (predominantemente crianças) e do trabalho dos palhaços doutores nas unidades hospitalares, sendo realizadas observações no local e entrevistas com a equipe médica nos 5 hospitais de atuação do grupo. Balizados pela proposta metodológica de Löbach (2001), foram definidos ferramentas e métodos para auxiliar a prática projetual, utilizando-se referências estéticas, técnicas e funcionais, com a finalidade de resultar na criação de um carrinho de leitura, para melhorar a experiência do paciente durante a internação, com foco na relação do ergodesign com o lúdico.

Palavras-chave: design hospitalar, ergodesign, metodologia de produto, ludicidade

\section{INTRODUÇÃO}

A ideia de reunir pessoas em espaço e oferecer assistência iniciou-se, segundo Campos (1965) em épocas passadas, nas casas de assistência, onde os peregrinos, pobres e enfermos eram recebidos, dando origem então ao hospital, de raiz latina (Hospitalis) vem de hospes (hóspedes). Na atualidade, o hospital deixa de ser uma simples figura arquitetônica e passa a ser um instrumento terapêutico de tratamento de doentes (FOUCAULT, 1992).

Desse modo, o processo de internação em uma unidade hospitalar pode comprometer o paciente no que compete as suas dimensões, físicas, psíquicas, culturais, espirituais, sociais e intelectual (BRASIL \& SCHWARTZ, 2005). Sendo uma experiência que pode ser traumática para qualquer pessoa, seja ela adulta ou criança.

Para a criança esse período de internação, pode contribuir para regressão do tratamento, de acordo com Martins e Souza (2013) esse cotidiano não familiar, deixa a criança mais suscetível a estar amedrontada, angustiada, ansiosa, com medo e triste. Dessa forma, o ato de brincar, segundo Barros e Lustosa (2009) é um suporte para que a criança possa atingir seu desenvolvimento sócio, emocional e cognitivo, o brincar transforma o ambiente hospitalar, por intermédio do brinquedo a criança passa a se desenvolver, estimulando a criatividade, a autoconfiança, autonomia e a curiosidade, assim como, melhorar o seu convívio social (FROTA, 2007). 
O Ministério da Saúde (2001), por meio do Programa Nacional de Humanização da Assistência Hospitalar - PNHAH (2001), define humanização como o processo de alcançar benefícios mútuos para a saúde do usuário e do profissional de saúde. Dessa necessidade de humanização hospitalar, baseados nos princípios da "sorrisoterapia", segundo Cavalcante (2016) é o sorriso como recurso terapêutico, desse modo, surgiram nos últimos anos, de forma que grupos/organizações procuram através de processos lúdicos, melhorar o processo de hospitalização.

Esses grupos atuam dentro dos hospitais, em geral, nas brinquedotecas que são ambientes elaborados com a intenção de permitir múltiplas atividades recreativas, lúdicas e estimuladoras (SANTOS, 2015). Contudo, existem intervenções que são realizadas fora das brinquedotecas, nos leitos e em outras alas médicas mais específicas, pois o paciente não consegue se deslocar até a brinquedoteca.

Dessa forma, os palhaços doutores (como são denominados os integrantes dos grupos), inseridos no ambiente hospitalar, procuram uma interação com a criança através de criatividade e improvisação, que tem por objetivo proporcionar um momento de descontração minimizando assim o estresse do tratamento (CAVALCANTE, 2016).

Figura 1 - Configuração esquemática do processo de Humanização. Fonte: elaborado pelos autores, com base na pesquisa realizada (2017).

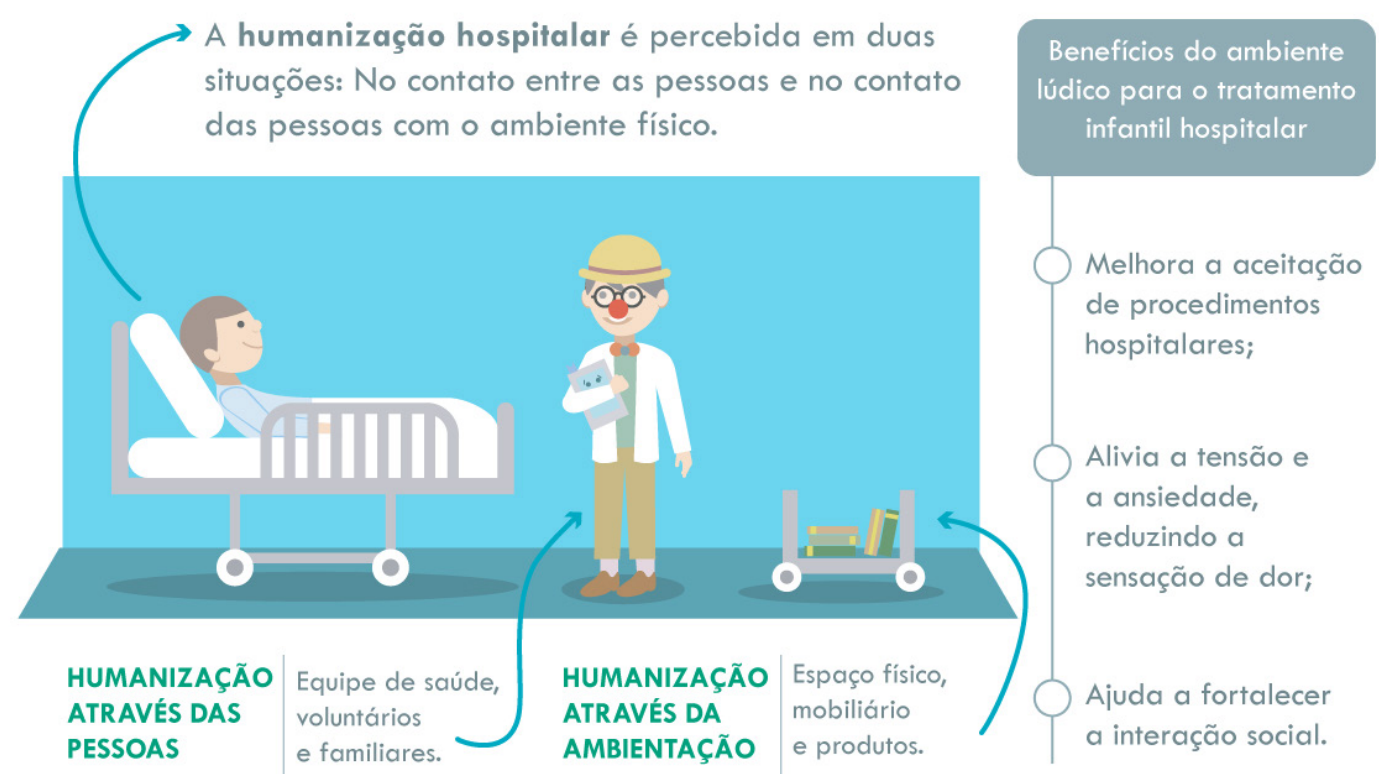

Assim, são diversas as práticas adotadas para essa interação, que incluem o uso de performances musicais, teatrais, brinquedos, conversas, pinturas, desenhos e leituras, dentre outros.

Dentro desse contexto, uma dessas práticas pode ser a utilização de um produto que possa estimular e auxiliar essa interação, assim, cabe ao design através da aplicação de ferramentas e métodos de pesquisa, elaborar projetos que contemplem essa humanização de assistência à saúde, conferindo serviços, produtos e/ou sistemas aos usuários hospitalizados e aos trabalhadores da saúde, conforme a figura 2. 
Figura 2 - Abordagem do designer no ambiente hospitalar. Fonte: elaborado pelos autores, com base na pesquisa realizada (2017).

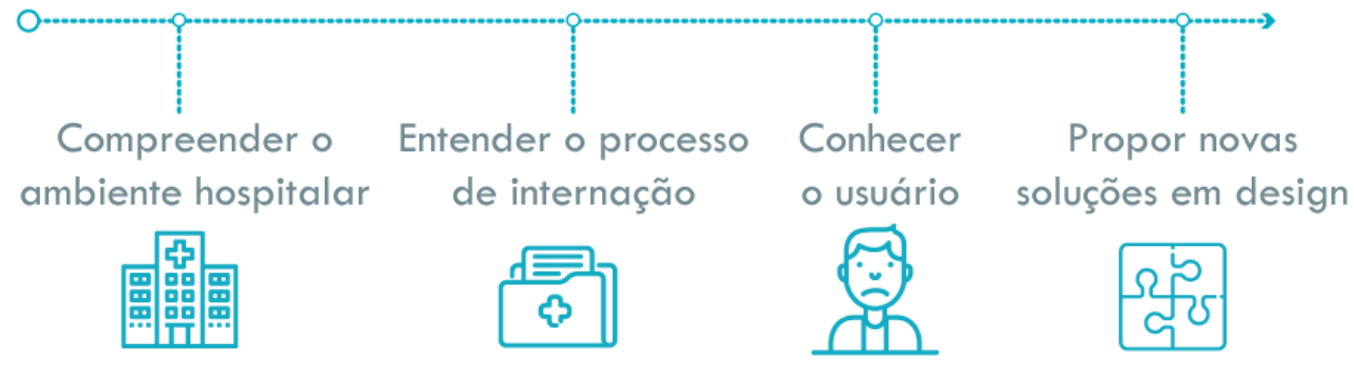

Desse modo, a partir de visitas aos hospitais juntamente com o grupo Sorriso de Plantão nas alas pediátricas, constatou-se que esses profissionais lidam com as crianças utilizando o lúdico como recurso terapêutico no processo de internação, sabe-se que essa utilização se dá de três formas: pelo contato direto com o paciente, pela ambientação física do hospital e com o uso de produtos, conforme pode ser vista na atuação do grupo, figura 3.

Figura 3 - Atuação do Grupo Sorriso de Plantão no Hospital Santa Casa em Maceió-AL. Fonte: http://www. sorrisodeplantao.com.br, fotografia Cristiane Costa (2016).

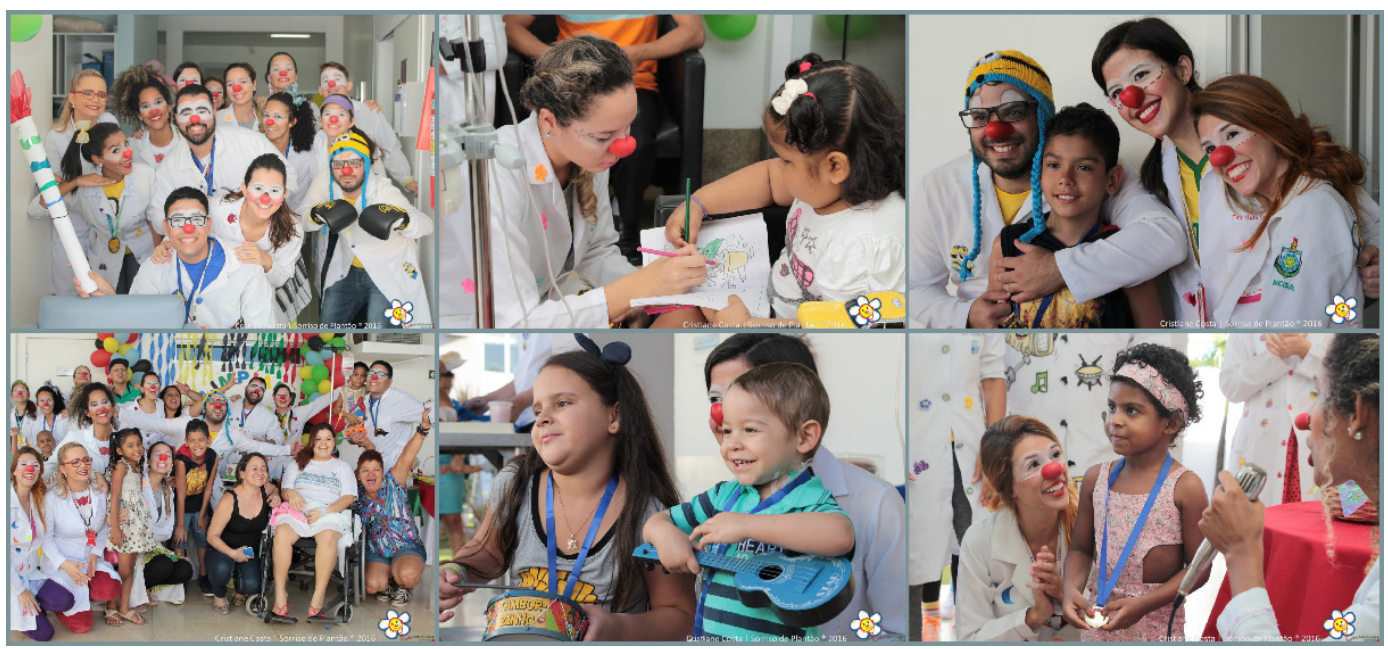

Após métodos observacionais e interacionais em conjunto com Grupo supracitado, foi identificado o objetivo do projeto, descrito na figura 4.

Figura 4 - Objetivo definido para o projeto. Fonte: elaborado pelos autores, com base na pesquisa realizada (2017).

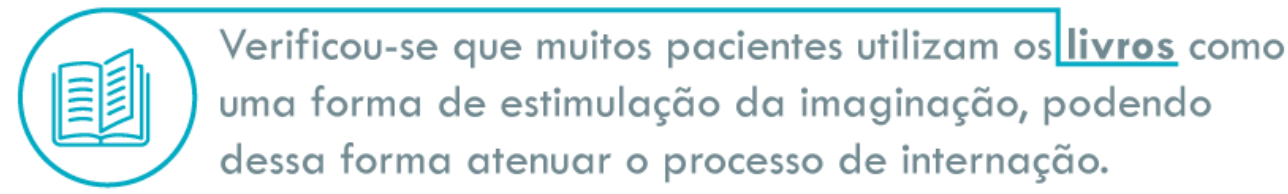

Foi possível inferir que, desenvolver de um Carrinho que potencializasse essas relações com os livros irá melhorar a experiência das crianças durante a internação hospitalar.

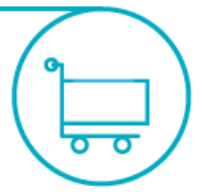

Assim, esse projeto de pesquisa apresenta como objetivo, melhorar o processo de internação de crianças, através inserção de um produto no contexto hospitalar, assim, será desenvolvido um carrinho de leitura, com foco na relação do ergodesign com o 
lúdico.

Para validar o desenvolvimento da pesquisa e a criação de um produto, será utilizada inicialmente a abordagem do método da Pesquisa-Ação (P.A.) proposta por Thiollent (2003), que caracteriza-se pela participação do pesquisador no interior do objeto de pesquisa, dessa forma, unindo a pesquisa teórica a objetivos concretos a fim de melhorar os processos de aprendizagem e posteriormente será utilizada a metodologia modelada de Löbach (2001) com ferramentas propostas por Baxter (2011), Moraes e Mont'Alvão (2009) e Stickdorn (2014), definindo assim o processo metodológico abordado nessa pesquisa. O próximo tópico tem como objetivo conceituar as macros áreas dessa pesquisa.

\section{CONTEXTUALIZAC̣ÃO: ERGODESIGN E LUDICIDADE}

Como já visto anteriormente a presença do lúdico nos ambientes hospitalares, contribui para uma melhora significativa dos pacientes, nessa pesquisa esse diagnóstico foi percebido na revisão bibliográfica e validado de maneira preliminar no primeiro contato com os usuários nas visitas às unidades hospitalares, com o grupo Sorriso de Plantão da cidade de Maceió-AL.

O grupo Sorriso de Plantão, ver figura 5, é um projeto de extensão universitária da Universidade Federal de Alagoas (UFAL), em parceria com a Pró-reitoria de Extensão da Universidade Estadual de Ciências da Saúde de Alagoas (UNCISAL) que através do conceito dos palhaços doutores (pessoas que se caracterizam como palhaços e visitam unidades hospitalares) promovem atividades lúdicas com os pacientes.

Figura 5 - Configuração esquemática do Grupo Sorriso de Plantão. Fonte: elaborado pelos autores, com base na pesquisa realizada (2017).

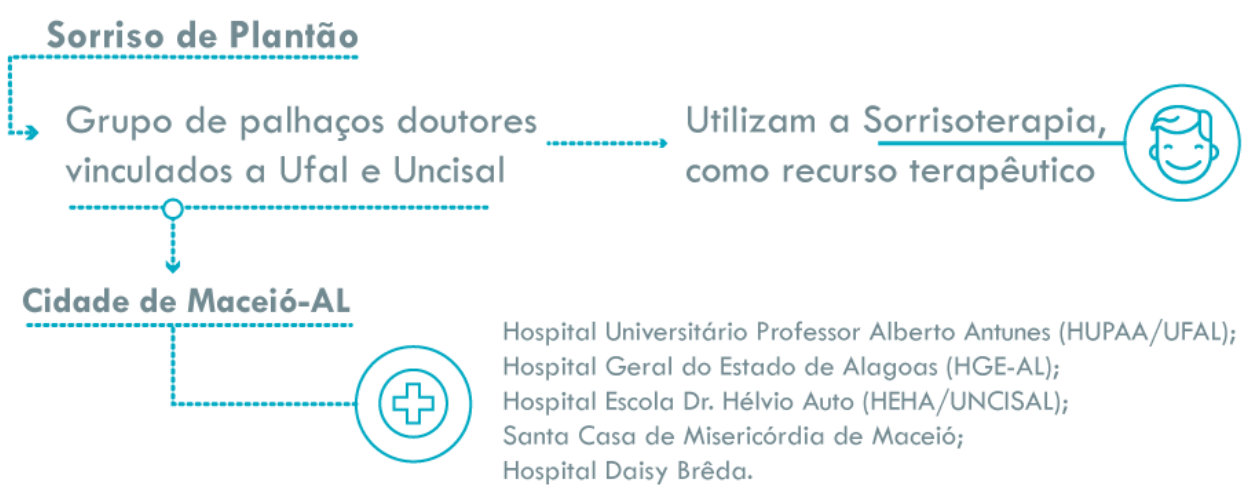

Dessa forma se faz necessário, reconhecer esses agentes (nessa pesquisa, o grupo Sorriso de Plantão) que irá colaborar com a prática projetual da pesquisa e auxiliar fases metodológicas, contribuindo para o equacionamento do problema e na obtenção de informações (THIOLLENT, 2003).

Assim, após a revisão bibliográfica e validação preliminar dos dados, é introduzido na pesquisa conceitos de ergodesign e design lúdico no contexto hospitalar.

Saúde, segundo a Organização Mundial da Saúde - OMS (1983), não é apenas a ausência de uma doença, mas também a situação que compreende o bem-estar, físico e mental das pessoas, uma vez que esse propósito não está restrito aos profissionais da saúde, o design, dentro do cenário hospitalar, buscar melhorar sistemas, produtos e serviços através do planejamento, desenvolvimento, seleção de materiais, uso da tecnologia e prática sustentáveis. 
Uma das áreas ligadas ao design que é responsável por tornar estes espaços mais acolhedores e confortáveis aos pacientes, através da utilização de produtos, é o ergodesign, estudos desenvolvidos, por Moraes (2013) apud Yap (1997), apontam que esse é um termo novo, que tem origem na união entre as disciplinas: a ergonomia (estudo do trabalho) e o design (desenvolvimento de projetos), tem-se nessa relação uma ponte entre as duas áreas, para que essa junção resulte na melhoria do processo de criação de novos produtos, conforme pode ser verificado na figura 6, onde o foco de atuação seja o usuário e sua relação com qualquer interface de qualquer produto, sistemas ou ambientes.

Figura 6 - Macro áreas do Ergodesign de produto. Fonte: elaborado pelos autores, com base na pesquisa realizada (2017).

\section{ERGODESIGN DO PRODUTO}

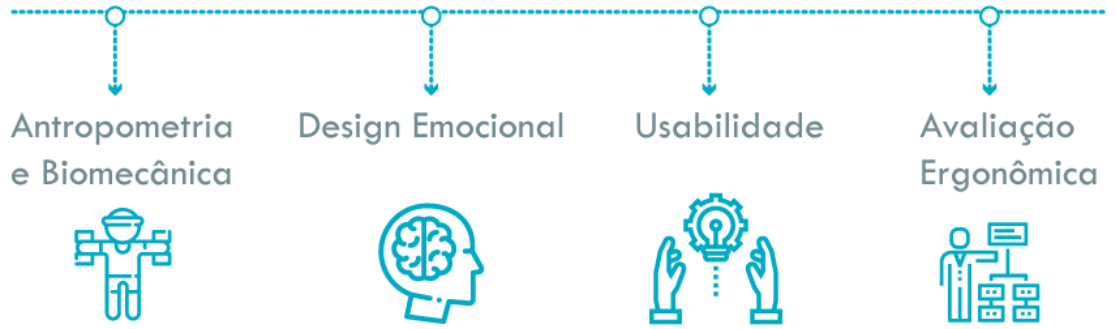

Diante da possibilidade de trazer o lúdico para o desenvolvimento de um produto, no contexto hospitalar, deve-se observar a definição proposta por Brasil \& Schwartz (2005) o lúdico, é associado jogo, ao brinquedo a diversão, de maneira geral é tudo aquilo que provoca, alegria, emoção espiritualidade, assim, como funciona como mediador do processo de aprendizagem, sendo então um veículo de desenvolvimento afetivo, motor, mental, intelectual e social do indivíduo, tornando-se uma ponte entre o real e o idealizado (FROTA, 2007).

Para o desenvolvimento do produto desse projeto, pretende-se que o design possa incorporar o lúdico como requisito projetual, tornando-o assim, mais acolhedor, interativo e estimulante de modo a intensificar os benefícios do tratamento. Os objetivos da ludicidade estão descritos na figura 7, a seguir:

Figura 7 - Objetivos da Ludicidade. Fonte: elaborado pelos autores, com base na pesquisa realizada (2017).

\section{LUDICIDADE}

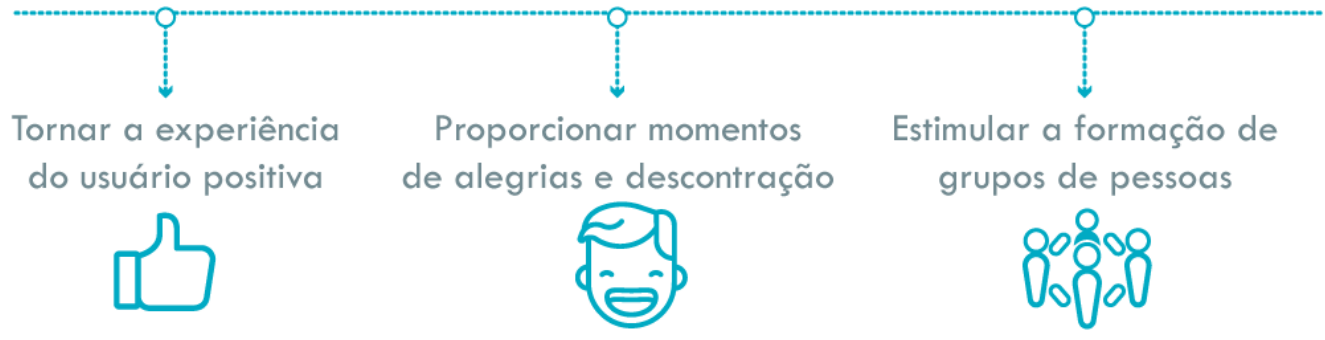

Estudos propostos por Desmet (2009), mostram que existem 4 tipos de abordagens, para os trabalhos de design com foco nas emoções no desenvolvimento de produtos: 1) Abordagem Com foco no usuário; 2) Abordagem com foco nos designers; 3) Abordagem com foco em pesquisa; e 4) Abordagem com foco em teoria. Assim, o que também é necessário em um produto, são as histórias de interação, de como as pessoas fazem essas associações com o objeto e das lembranças que ele evoca (NORMAN, 2008).

A partir dos estudos sobre o tema e das análises nos hospitais, entendesse que o desenvolvimento de produtos que utilize requisitos e parâmetros estéticos, funcionais e técnicos a fim de comtemplar de forma satisfatória esses ambientes é necessário. 
O processo metodológico, já mencionado anteriormente, divide-se em quatro fases, o próximo tópico irá abordar sobre a inserção da metodologia no projeto.

\section{METODOLOGIA: FERRAMENTAS E MÉTODOS}

A pesquisa realizada para este projeto, fundamenta-se na revisão bibliográfica sobre o tema proposto, assim como, pesquisa in loco, nos hospitais de atuação do Grupo Sorriso de Plantão, na cidade de Maceió-AL. Desse modo, o processo metodológico utilizado no desenvolvimento da pesquisa. Utilizou-se do método da (P.A.) proposto por Thiollent (2003) e da metodologia modelada de Löbach (2001).

Figura 8 - EAP do projeto para o desenvolvimento do carrinho, com as ferramentas. Fonte: elaborado pelos autores, com base na pesquisa realizada (2017).

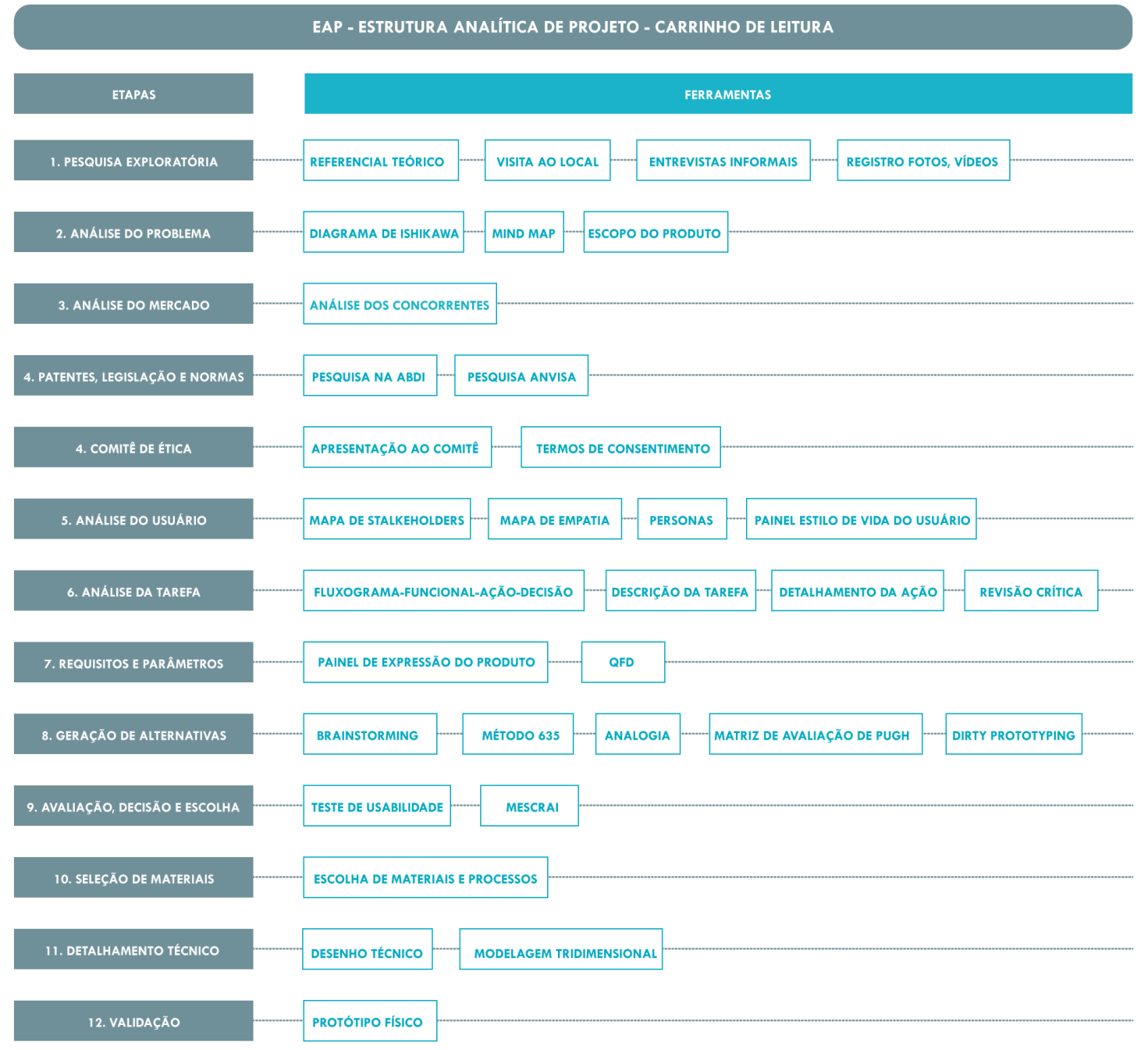

Dessa forma, para definir o tema da pesquisa e traçar um diagnóstico sobre a atual situação do contexto, foi realizada uma pesquisa preliminar sobre o design hospitalar (atuação e limites da área), observou-se que que existe muito estudo na área, porém pouca aplicação prática no desenvolvimento de produtos, posteriormente para a validação preliminar dos dados, foi realizada uma visita aos 5 hospitais de atuação do Grupo Sorriso de Plantão, onde cada unidade possui um ambiente de acomodação do grupo (podendo ser um espaço de brinquedoteca ou não), dessa observação, verificouse os limites do espaço físico, os condicionantes ambientais, assim como a atividade realizada pelos integrantes que compõem o grupo.

As primeiras validações que compõe essa pesquisa, foram obtidas, através dessa visita 
aos hospitais, por meio de observação da atividade, observação dos espaços, entrevistas informais, registro de imagens e vídeos, que mostram a realidade do contexto no qual o produto deve ser inserido.

Após essa abordagem, ocorre a hierarquização das demandas, definindo os objetivos específicos da pesquisa: 1) Conhecer o mercado de produtos hospitalares; 2) Levantar dados sobre a atuação do design lúdico; 3) Identificar a relação do usuário com o produto pelo viés emocional; 4) Definir requisitos de projeto, para o desenvolvimento de produtos hospitalares; 5) Validar a metodologia para o desenvolvimento de projetos no design.

6) Aplicar o Ergodesign no desenvolvimento de produtos e 6) Expandir a produção e pesquisa em design e saúde.

Para a etapa final, será utilizada a metodologia de Design Industrial, proposta por Löbach (2001), com o auxílio das ferramentas e técnicas de Baxter (2011), Moraes e Mont'Alvão (2009) e Stickdorn (2014) e Rozenfeld (2006). Assim Lobach (2001) divide o processo de design, em 4 macro fases: I) Análise do Problema; II) Geração de alternativas, III) Avaliação das Alternativas e IV) Solução do problema.

Na etapa de Análise do Problema, é realizada a identificação do problema, validação da necessidade, e definição do objetivo, sendo possível definir as metas ao longo do processo projetual. Será utilizada nesta etapa, as ferramentas de Diagrama de Ishikawa proposto por Kaoru Ishikawa (1943) e o Mind Map de Tony Buzan (2005) com a finalidade de visualizar, agrupar e organizar as ideias a partir do repertório obtido da pesquisa Desk, para que possa conhecer os problemas e seus desdobramentos, para assim gerar o Escopo do produto (Rozenfeld, 2006), um documento que sintetiza as características e funções que o produto deverá apresentar.

Uma vez que se conhece o contexto do produto se faz necessário a próxima etapa que consiste na Análise do mercado, através da ferramenta de Baxter (2011) Análise dos Concorrentes, onde é possível conhecer os produtos similares disponíveis no mercado, analisando-os sob vários aspectos, dentre eles podem ser: antropológicos, ecológicos, econômicos, ergonômicos, filosóficos, geométricos, mercadológicos, psicológicos; estruturais, funcionais e tecnológicos. Essa análise tanto pode ser qualitativa e/ou quantitativa, estrutura em tabelas, de forma comparativa.

A próxima fase, consiste numa pesquisa mais aprofundada, dando início a fase de Patentes, legislação e normas, por se tratar de um produto hospitalar a Agência Nacional de Vigilância Sanitária - Anvisa (2010), por meio da Agência Brasileira de Desenvolvimento Industrial - ABDI (2010) dispõe de forma online um Manual para Registro de Equipamentos Médicos, no próprio Manual é possível identificar alguns parâmetros para o desenvolvimento de produto, essa fase é de extrema importância, uma vez que esses dados obtidos, irá compor o quadro de requisitos do projeto.

Para preservar a identidade dos participantes, nesta fase, deve-se apresentar o trabalho ao Comitê de ética em Pesquisas nos hospitais e o mesmo deverá aprová-lo.

A partir do contexto do produto, se faz necessário conhecer quem são os usuários envolvidos no projeto, essa fase é conhecida como Análise do Usuário, após as primeiras entrevistas é definido de acordo com Stickdorn, o Mapa de Stakeholders (2014) da pesquisa, após será construído o Mapa de Empatia (2005) de Scott Matthews e a criação de Personas também de Stickdorn (2014), com o objetivo de traçar um perfil hipotético do usuário baseado nas observações e na entrevista, por fim, é utilizado o Painel do estilo de vida do usuário proposto por Baxter (2011) que tem como objetivo construir uma síntese visual a partir de imagens, para refletir os valores pessoais e sociais desses usuários.

Em seguida, é introduzida a aplicação do ergodesign no projeto, primeiro é realizada 
uma pesquisa sobre Biomecânica e antropometria, considerando os usuários envolvidos no processo da pesquisa, posteriormente é realizada a Análise da tarefa, através da utilização do Fluxograma - Funcional - Ação - Decisão proposto por Moraes \& Mont'Alvão (2009) onde o projetista consegue ter uma visão macro do sistema com seus subsistemas, nesta etapa é possível compreender o tipo de trabalho, identificar as alternâncias das posturas, pegas e manejos, sendo ela realizada em três níveis, a) descrição da tarefa, b) detalhamento da ação, e c) revisão crítica (IIDA, 2005).

Para estruturar os requisitos e parâmetros do produto, serão utilizados os Painéis de expressão do produto e tema visual do produto de Baxter (2011), posteriormente será aplicado o Quality Function Deployment - QFD (ROZENFELD, 2006) esse método, tem o objetivo de hierarquizar os problemas encontrados levando em contas os principais aspectos ergonômicos, técnicos e estéticos no desenvolvimento de produtos (IIDA, 2005).

Desse modo, finalizadas essas etapas, dá-se início o processo criativo, com a geração de alternativas, é "a fase da produção de ideias, baseando-se nas análises realizadas" (LOBACH, 2001), desse modo, nessa etapa será utilizada o Brainstorming (Osborn, A.1953) é um método que possui muitas variações, que possibilita registrar o maior número de ideias sobre um determinado tema, nesta pesquisa, esse método, pode ser realizado de maneira coletiva, com a equipe dos palhaços doutores. E posteriormente será aplicada a ferramenta Método 635, proposta por Baxter (2011): (seis pessoas, três ideias em cinco minutos), segundo o autor, a criatividade é o coração do design e o projetista deve ousar nesta etapa.

Assim, através de esboços é aplicada a ferramenta "Analogias", também proposta de Baxter (2001) que consiste em associar as propriedades de um determinado conceito ao produto. Desse modo, as principais alternativas serão definidas com base na aplicação na matriz de avaliação de Pugh (1991) proposta por de Stuart Pugh, que tem como objetivo atribuir pesos, a partir de critérios pré-estabelecidos, ao final da avaliação, deve-se verificar quais foram as alternativas com maior peso. Posteriormente é realizada uma hierarquização, as mais votadas passam para a próxima etapa que consiste na aplicação do Dirty Prototyping proposta do Design Thinking (Brown, 2010) onde as alternativas são visualizadas tridimensionalmente, confeccionadas em materiais diversos, resultando na construção de mockups do produto.

Da análise dos mockups, para a fase de avaliação, decisão e escolha, é feito o teste de usabilidade, que corresponde na interação entre produto, o usuário, a tarefa e o ambiente (IIDA, 2005) e posteriormente será aplicada a fermenta MESCRAI (Baxter, 2011) que funciona como uma lista de verificação para as estimular as possíveis modificações que o produto pode incorporar em seu desenvolvimento, assim, MESCRAI, significa, Modificar, E Liminar, Substituir, Combinar, Rearranjar, Adaptar e Inverter. Em paralelo também ocorre a fase de seleção de materiais, segundo Ashby \& Johnson (2011) esse ato, visa converter uma lista de insumos (requisitos de projeto) em uma lista de materiais e processos viáveis, que pode ser feito por a) análise, b) síntese, c) similaridade e d) inspiração, ou pela combinação de dois ou mais.

Assim, a fase final consiste no detalhamento técnico do produto realizado no programa

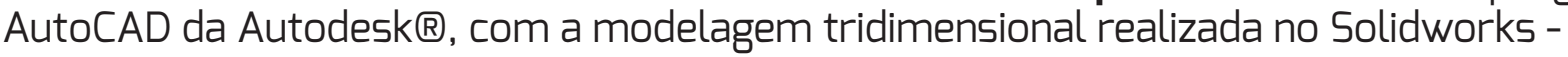
SKA @ no e protótipo físico, com materiais similares, para ser testado pelos usuários, validando assim o produto.

\section{CONSIDERAÇÕES FINAIS}

Dessa forma, com base nas informações levantadas durante o referencial teórico, 
a presente pesquisa aqui propõe uma imersão no contexto do ambiente hospitalar, do processo de internação e o do uso do lúdico como recurso terapêutico.

Foi abordado o primeiro contato com o contexto hospitalar através do Grupo Sorriso de Plantão, sendo definidas algumas demandas e apontado um objetivo que envolvesse a atuação do designer na solução de novos, sistemas ou produtos. Assim, fica evidente, o uso positivo dos métodos propostos pela Pesquisa Ação, através de métodos observacionais e interacionais.

A proposta metodológica para o desenvolvimento do carrinho, foi realizada a partir da vivência dos autores e das pesquisas sobre metodologia em Design de Produto, a EAP, permitiu melhorar a visualização do processo, assim foram propostas macros fases e ferramentas de modo a validar e justificar a metodologia modelada de Löbach (2001), uma vez que o presente trabalho se encontra ainda na fase inicial da pesquisa exploratória. Sendo proposta uma metodologia, com base nas pesquisas dos autores.

Com isso, foi possível verificar a lacuna de produtos hospitalares existentes e um campo de atuação novo e emergente que são os produtos lúdicos hospitalares. Outrossim, vale salientar o destaque e a importância da produção de pesquisas que convergem para soluções de produtos hospitalares, ou para meios que cheguem a esse fim. Dessa forma, deve-se considerar a atuação do designer como intermediador entre pessoas e produtos, a fim de maximizar e melhorar as possíveis interações entre ambos.

\section{REFERÊNCIAS}

ASHBY, Michael F.; JOHNSON, Kara. Materiais e Design: Arte e Ciências da Seleção de Materiais do Design do Produto. 2. ed. Rio de Janeiro: Campus, 2010.

BARROS, Danielle Marotti de Souza; LUSTOSA, Maria Alice. A ludoterapia na doença crônica infantil. Rev. SBPH v. 12 n. 2, Rio de Janeiro, dez., 2009.

BRASIL, Maria de Lourdes Silveira; SCHWARTZ, Eda. As atividades lúdicas em unidades de hemodiálise. Acta Scientiarum, Maringá, v. 27, n. 2, p.103-112, 2005.

BAXTER, Mike. Projeto de Produto: Guia prático para o design de novos produtos. São Paulo: Edgard Blücher, 2011.

CAVALCANTE, A. L. ; VAlENTIM, D. S. ; SANTOS, L. G. M. L. ; ALBUQUERQUE, M. C. 5. ; SILVA, M. R. . O sorriso como recurso terapêutico à criança hospitalizada: Lições dos palhaços doutores do grupo Sorriso de Plantão para um cuidado humanizado. Cadernos de Graduação do Grupo Tiradentes , v. 3, p. 43-56, 2016.

CAMPOS, E. de S. Evolução dos hospitais. In: Ministério da Saúde. História e evolução dos hospitais (volume 1). Rio de Janeiro, 1944 - reedição de 1965.

DESMET, P. Special Issue Editorial: Design \& Emotion. International Journal of Design, 2009.

FOUCAULT, M. Microfísica do Poder. 10. ed. Organização e tradução de Roberto Machado. Rio de Janeiro,Graal, 1992.

FROTA, Mirna Albuquerque et al. 0 Lúdico como Instrumento facilitador na Humanização do Cuidado de Crianças Hospitalizadas. Cogitare Enferm 2007 jan/mar; 12(1):69-75.

GONÇALVES, Ana Elise da Silva; ROMANO, Fabiane Vieira; BATTISTEL, Amara Lúcia Holanda Tavares. Design Lúdico: carrinho para auxiliar o tratamento oncológico infantil., p. 3564-3575. In: Anais do 110 Congresso Brasileiro de Pesquisa e Desenvolvimento em 
Design Blucher Design Proceedings, v. 1, n. 4]. São Paulo: Blucher, 2014.

IIDA, Itiro. Ergonomia - Projeto e Produção. 2a ed. São Paulo: Blucher, 2005.

LÖBACH, Bernd. Design Industrial: bases para a configuração dos produtos industriais. Tradução por Freddy Van Camp. 1. ed. São Paulo: Edgard Blücher, 2001.

Manual para registro de equipamentos médicos na Anvisa / Agência Brasileira de Desenvolvimento Industrial. - Brasília: ABDI, 2010.

MORAES, A. de. Ergonomia, Ergodesign e Usabilidade: algumas histórias, precursores; divergências e convergências. In: Anais do I Ergodesign. Rio de Janeiro: PUC-Rio, 2001.

MORAES, A. e MONT'ALVÃO, C. Ergonomia Conceitos e Aplicações. 4a ed., Rio de Janeiro: 2AB, 2009.

NORMAN, Donald. Design Emocional: Por que adoramos (ou detestamos) os objetos do dia-a-dia. Rio de Janeiro: Rocco. 2008.

ROZENFELD, H.; FORCELLINI, F. A.; AMARAL, D. C.; et al. Gestão de Desenvolvimento de Produto: uma referência para a melhoria do processo. 1 ed. São Paulo: Saraiva, 2006.

SOUZA, G.; MARTINS, M. A brinquedoteca hospitalar e a recuperação de crianças internadas: Revisão bibliográfica. Revista Saúde e Pesquisa, Bahia, v. 6, n. 1, p. 123130 , jan./abr. 2013.

SANTOS, Danielle Maria Lamenha; ROCHA, Cora G. Brinquedoteca em Instituição de Apoio Hospitalar: brincar para curar. In: 7 Projetar, 2015, Natal, RN. Caderno de Resumos on-line: Originalidade, criatividade e inovação no projeto contemporâneo: ensino, pesquisa e prática. Natal, RN: FIRENZZE, 2015.

STICKDORN; J. SCHNEIDER (orgs.), Isto é Design thinking de serviços: Fundamentos Ferramentas - Casos. Porto Alegre, Bookman, 2014

THIOLLENT, Michel. Metodologia da Pesquisa-Ação. São Paulo. Cortez, 2002.

Sobre os autores:

Sandro Alisson Neris dos Santos (graduando), UFAL < neris.sandroalisson旬gmail.com> Juliana Donato de Almeida Cantalice (doutoranda), UFAL < juliana.donato@fau.ufal.br> 